\title{
Obstructive sleep apnea and ocular disorders.
}

Deepak P. Grover

Wills Eye Institute, Thomas Jefferson University

Follow this and additional works at: https://jdc.jefferson.edu/willsfp

Part of the Ophthalmology Commons

Let us know how access to this document benefits you

\section{Recommended Citation}

Grover, Deepak P., "Obstructive sleep apnea and ocular disorders." (2010). Wills Eye Hospital

Papers. Paper 8.

https://jdc.jefferson.edu/willsfp/8

This Article is brought to you for free and open access by the Jefferson Digital Commons. The Jefferson Digital Commons is a service of Thomas Jefferson University's Center for Teaching and Learning (CTL). The Commons is a showcase for Jefferson books and journals, peer-reviewed scholarly publications, unique historical collections from the University archives, and teaching tools. The Jefferson Digital Commons allows researchers and interested readers anywhere in the world to learn about and keep up to date with Jefferson scholarship. This article has been accepted for inclusion in Wills Eye Hospital Papers by an authorized administrator of the Jefferson Digital Commons. For more information, please contact: JeffersonDigitalCommons@jefferson.edu. 


\title{
As submitted to:
}

\section{Current Opinion in Ophthalmology}

\author{
And later published as:
}

"Obstructive Sleep Apnea and Ocular Disorders"

\author{
Volume 21, Issue 6, November 2010, p 454-458
}

DOI: 10.1097/ICU.0b013e32833f00dc

Deepak P. Grover

Wills Eye Institute, Thomas Jefferson University

Department of Neuro-Ophthalmology

Philadelphia, Pennsylvania, USA

Correspondence to Deepak P. Grover, DO

Neuro-Ophthalmologic Associates, PC

Wills Eye Institute 
840 Walnut Street, Suite 930

Philadelphia, PA 19107, USA

Tel: +1 2159283130

Email: DeepakPGrover@gmail.com

\section{Purpose of review}

Obstructive sleep apnea is a diagnosis that non-primary care physicians can screen for when a patient presents with certain risk factors. Recent literature provides strong data for associations between sleep apnea and ocular disorders.

\section{Recent findings}

A potentially serious disorder, sleep apnea can lead to many systemic and ocular complications. Recent findings provide data on the prevalence of sleep apnea with various disorders. Adequate treatment of sleep apnea has also shown to reverse both systemic and eye related complications.

\section{Summary}


Early diagnosis and management of sleep apnea is critical for reducing the risk of devastating systemic complications and preserving ocular and visual function. Further longitudinal data is needed to see the effectivity of long term management of sleep apnea and its impact on reversing associated complications.

\section{Keywords}

obstructive sleep apnea, ocular disorders, floppy eyelid syndrome, glaucoma, non-arteritic ischemic optic neuropathy, central serous chorioretinopathy, retinal vein occlusion

\section{Introduction}

Obstructive sleep apnea (OSA) is a potentially serious sleep disorder characterized by recurrent episodes of breathing cessation during sleep secondary to an upper airway collapse (1). Complete apnea or partial hypopnea episodes can last from 10-30 seconds and may occur up to hundreds of times nightly. It is often accompanied with swings in heart rate, a decrease in oxygen saturation, and brief electroencephalogram arousals.

Sleep apnea is a disorder not commonly diagnosed by the ophthalmologist, but an important one that has many systemic and ocular complications. Furthermore, it is undertreated as patients defer treatment with a continuous positive airway pressure (CPAP) mask, however, it can be reversed quickly with appropriate 
treatment. Sleep apnea carries significant morbidity with a higher incidence of cardiovascular and cerebral sequelae (2-3). It is associated with hypertension, diabetes, coronary artery disease, congestive heart failure (4-5), atrial fibrillation (6); all of which may predispose one to a stroke. Additionally, OSA has also recently been identified as an independent risk factor for stroke (7)••. There is also increasing evidence that OSA coexists in epilepsy and that CPAP treatment improves seizure control, cognitive performance and quality of life (8).

\section{Epidemiology}

Sleep apnea is an increasingly prevalent condition in both adults and children. Approximately $24 \%$ of men and $9 \%$ of women have OSA, with and without excessive daytime sleepiness (9). In children, OSA is a common but underdiagnosed condition, where the exact prevalence is less certain. One study suggested approximately $6 \%$ of adolescents may have sleep-related disordered breathing (10). Many of these children present with obesity and excessive daytime sleepiness and/or hyperactivity.

\section{Pathophysiology}

An anatomical deficiency of the upper airway is regarded as the most accepted theory regarding the pathogenesis of OSA. Schwab et al. explained the increase soft tissue volume of soft palate, tongue, parapharyngeal fat pads and lateral pharyngeal walls (11-13). Patients with OSA seem to also have a smaller and an oval shaped pharyngeal airway with the long axis in the anterior-posterior orientation as opposed to the short axis in the anterior-posterior orientation when compared to healthy subjects. Longer airways are more easily collapsible than shorter airways and this recurrent pharyngeal collapse directly obstructs the upper airway. 


\section{Predisposing factors}

Excess weight and fat deposit around the upper airway may obstruct breathing. An increase in neck circumference may also narrow the airway. A neck circumference greater than 17 inches (43 centimeters) for males and 15 inches ( 38 centimeters) for females is associated with an increased risk. Chronic nasal congestion can also narrow the upper airway. There is a relative increase in risk with hypertension and a three-fold increase in patients with diabetes. Men are twice as likely as women to develop sleep apnea. Among people under the age of 35, OSA is more common in blacks, Hispanics and Pacific Islanders. Sleep apnea is three times more common in adults over the age of 65. Menopause appears to increase the risk in females. Smokers have a three-fold increase than non-smokers and alcohol intake increases the risk by relaxing the muscles in the throat.

\section{Clinical Manifestations}

The three cardinal symptoms of OSA include loud snoring, excessive daytime sleepiness and apnea episodes. Observed episodes of breathing cessation during sleep and abrupt awakenings accompanied by shortness of breath are common complaints. Other features include awakening with a dry mouth or sore throat, morning headache, frequent urination at night and insomnia.

\section{Diagnosis}

The Epworth sleepiness scale is widely used as a screening test for OSA at a cutoff of 10 points (14). Tests to detect sleep apnea include nocturnal polysomnography, oximetry and portable cardiorespiratory testing. During nocturnal polysomnography testing, the physician can monitor the functions of the heart, 
lungs and brain as well as rule out other conditions that can cause excessive daytime sleepiness. Pulse oximetry readings will often be low during apnea with normalization upon awakening. A portable cardiorepiratory testing device provides the patient the ability with a take-at-home test that measures oximetry, along with airflow and breathing pattern measurements.

\section{Management}

\section{Medical management}

Treatment with CPAP quickly reverses symptoms of excessive daytime sleepiness and aids in management of OSA. Continuous positive pressure, applied through a nasal mask, oronasal mask, or nasal pillows, acts as a pneumatic splint to maintain upper airway patency during sleep. Adequate treatment with CPAP has been demonstrated to show an over-recruitment of brain regions compared with controls using functional MRI scanning (15) •. For patients who cannot tolerate CPAP therapy, bilevel positive airway pressure (BiPAP) therapy is attempted next, which automatically adjusts the pressure while one is sleeping. An oral appliance device is attempted if BiPAP is not tolerable to open the throat by bringing the jaw forward. Additionally, modafinil 200-400mg/day has been shown to effectively enhance alertness in patients with daytime somnolence (16).

\section{Surgical management}

Surgical management is reserved for patients in whom medical treatment cannot be tolerated or has failed. Uvulopalatopharyngoplasty is the most common surgical procedure performed for adults with sleep apnea. It involves the removal of the tonsils, the uvula, the distal margin of the soft palate and the redundant pharyngeal tissue along with reshaping of the lateral pharyngeal walls. Genioglossus muscle advancement with hyoid myotomy can also be used to expand the upper airway. Maxillomandibular advancement osteotomy is usually reserved for patients in whom other surgical modalities fail. The 
airway is expanded as the midface, palate, and mandible are moved forward. Finally, although a tracheostomy may be the most effective, it is only reserved for patients with severe, life-threatening OSA in whom other surgical treatments have all failed. Somnoplasty, or radiofrequency volumetric tissue reduction of the soft palate, has recently generated much interest in treating OSA (17).

\section{Associated Ocular Disorders}

\section{Floppy eyelid syndrome}

Floppy eyelid syndrome (FES), first described in 1981 by Culbertson and Ostler (18), is characterized by elastic upper eyelids that are easily everted with minimal lateral traction, associated with a papillary conjunctivitis of the upper palpebral conjunctiva. A weak tarsal plate allows for the lid to fold upon itself with ease. Obesity may be a confounding factor in the association of FES and OSA as many patients with OSA suffer from obesity. Two recent studies provide insight into the role of obesity. Fowler and Dutton conducted a case-based retrospective review of their patients along with a literature review for FES crossreferenced with factors including obesity and OSA. From their combined data, the overall prevalence of sleep apnea in patients with lax eyelid was $16 \%$ compared with an estimated $9 \%$ to $24 \%$ in the general population. Of patients with lax eyelid syndrome, patients identified with OSA had a significant greater amount of individuals with obesity (76\% vs. $20 \%)$ than individuals without OSA. Although sleep apnea has been associated with FES, it did not seem to occur with greater frequency when compared to individuals with obesity without FES in this study. Hence, the relationship between OSA and FES did not seem to be a causal one, but an epiphenomenon related to common body habitus and gender (19) ••. A recent case control study was conducted examining the association of FES and OSA while controlling for BMI by Ezra et al. Their findings confirmed that OSA was significantly associated with FES, despite correcting for weight. One possible mechanism, as explained by Ezra, may lie in changes in central nervous system arousability in OSA. A decrease in cortical arousability may prevent these patients from 
being disturbed by extreme mechanical stress to the upper lid during sleep, which would normally cause an unaffected individual to wake from the mechanical stress (20) ••.

\section{Glaucoma}

Both normal tension (21-22) and primary open-angle glaucoma (23-24) have been associated with sleep apnea. Theories of mechanism include: 1) impaired optic nerve head blood flow secondary to episodes of apnea, 2) optic nerve vascular dysregulation secondary to arteriosclerosis and variations in arterial blood pressure, and 3) episodes of hypoxia (25). As ocular blood flow has been suggested as a mechanism in glaucoma, Karakucuk et al. investigated the prevalence of glaucoma and ocular blood flow with orbital color Doppler ultrasonography in patients with OSA (26) •. The study included 31 patients with a diagnosis of OSA and 25 health controls. Both groups had a similar distribution of other atherosclerotic risk factors affecting ocular blood flow as there was no statistical difference between the two groups. The prevalence of glaucoma was $12.9 \%$ amongst the OSA group, of which all patients belonged to the severe OSA group [apnea-hypopnea index (AHI) >30]. There was no statistical significance between

ophthalmic artery resistivity index (OARI), central retinal artery resistivity index (CRARI) and intraocular pressure (IOP) between patients and controls. There was a positive correlation between the OARI and mean defect (MD), CRARI and MD, and CRARI and loss variance (LV) values, suggesting that visual field defects may be due to defects in optic nerve perfusion. Also, a significant positive correlation was noted between IOP and the AHI, suggesting that increased IOP may reflect the severity of OSA. Kargi et al. used a scanning laser polarimeter to examine the retinal nerve fiber layer (RNFL) in 34 patients with OSA. The thickness was reduced in patients with OSA when compared to controls, as well, a correlation was noted between the decrease in thickness with the severity of sleep apnea (27).

\section{Non-Arteritic Ischemic Optic Neuropathy}


Mojon et al. has hypothesized several theories in a correlation between OSA and NAION. An ischemic event may be secondary to impaired optic nerve head blood flow autoregulation from apnea. Optic nerve vascular dysregulation may also be a result of variations in arterial blood pressure seen in OSA, which may be due to an imbalance between nitric oxide and endothelin. Additionally, direct damage by periods of hypoxia likely plays a role $(25,28)$. Older studies had noted visual field defects consistent with an optic neuropathy in patients with OSA, however, data had not demonstrated a direct causal relationship between OSA and visual field defects (28). Mojon et al., in a case series, noted a high prevalence of OSA in patients with NAION, where $71 \%$ patients with NAION had OSA versus $18 \%$ of control patients with OSA in a study of 34 patients. He explained this may be why $75 \%$ of all patients with NAION discovered visual loss upon awakening in the morning (29). Palombi et al. had noted an even higher prevalence in his study where $89 \%$ of patients with NAION had sleep apnea (30). Patient with NAION who may have symptoms of OSA should undergo polysomnography. It is yet to be studied, however, if treatment of OSA reduces the risk of occurrence or recurrence of NAION (31).

\section{Papilledema}

Bucci and Krohel first reported a case of papilledema in a patient with OSA in 1988 (32), who had surgical treatment correcting his OSA which resolved his papilledema. Since, then, numerous cases have been reported of patients found to have papilledema and idiopathic intracranial hypertension. Many of these patients, however, have had normal opening pressures on lumbar puncture. Correction of their OSA with CPAP treatment had resolved the papilledema (33-36). The normal intracranial pressure (ICP) was best explained by Sugita et al. (37) who monitored continuous ICP in patients with OSA. Although all patients had normal ICP during the daytime, large increases in nocturnal ICP occurred which correlated with apneic events. Additionally noted was the degree of increase in ICP which also correlated with the duration of the apnea. 
Until recently, the prevalence of OSA in patients with papilledema was not looked at. Peter et al. questioned 35 patients with OSA regarding visual symptoms suggestive of papilledema, where 40\% reported some symptoms suggestive of papilledema. Upon funduscopic examination, none of the patients had signs of papilledema. Although papilledema has been associated with patients with OSA in previous reports, it is not a frequent finding in patients with OSA (38) •

Bruce et al. (39) • recently conducted a retrospective chart review, looking at 721 patients, including 66 men and 655 women, with sleep apnea. This is the largest study to date of IIH in men. Men were more likely to have OSA ( $24 \%$ vs. $4 \%$ ) than women. Also, men were almost twice as likely to develop visual changes (35\% vs. $20 \%)$ and had fewer symptoms of headache (55\% vs. $75 \%)$ as compared to women.

The debate will continue if whether OSA is causal or a comorbidity amongst patients with IIH. If causal, we still do not have a plausible mechanism (40). Additional questions, as if the visual outcome in patients with increased ICP is affected by the presence of OSA needs to be looked at in future studies. Screening however, is recommended in all patients with OSA who may have visual symptoms (31).

\section{Central Serous Chorioretinopathy}

Patients with sleep apnea have increased levels of circulating epinephrine and norepinephrine. With elevated levels of catecholamines, OSA has been hypothesized to be a direct risk factor for central serous chorioretinopathy (CSCR). Leveque et al. examined 29 patients with CSCR in a retrospective casecontrolled study to assess the risk of sleep apnea. With the use of the Berlin Questionnaire for OSA, their study revealed $58.6 \%$ of patients with CSCR to be at an increased risk for OSA compared to the control group of $31 \%(41) \bullet$ Kloos et al. then reported that $22 \%$ of patients in his series of 36 patients, with acute or chronic CSCR, suffered from OSA compared to the general population (2-4\%) (42) •. More recently, Jain et al. reported the first case of bilateral CSCR in a 45-year-old male found to have OSA that resolved with treatment of his OSA. Within one week of starting CPAP treatment, the patient noted an 
improvement of his vision and his visual acuity improved from 20/30 in his right eye (OD) and 20/40 in his left eye (OS) to 20/20 OD and 20/25 OS. Additionally, his serous detachments had resolved on examination and on OCT (43) ••. The most important factor in managing CSCR is recognizing and removing any inciting risk factors, as its natural history is typically favorable with resolution within six months.

\section{Retinal Vein Occlusion}

Leroux les Jardins et al. recently investigated the association between retinal vein occlusions and OSA. They are the first to report three patients who presented with retinal vein occlusions and found to have OSA. They hypothesized, that retinal vein occlusions may be associated with OSA as they may be secondary to a slow-down of blood flow circulation secondary to hypoxemia and elevated nocturnal intracranial pressure. Strictly acting on the retinal microcirculation, OSA may directly have a causal effect on retinal vein occlusions (44).

\section{Conclusion}

References

1. Guilleminault C, Tilkian A, Dement WC. The sleep apnea syndromes. Annu Rev Med. 1976:27:465-84.

2. Ali LK, Avidan AY. Sleep-disordered breathing and stroke. Rev Neurol Dis. 2008 Fall;5(4):191-8.

3. Jennum P. Quality of life, co-morbidity and obstructive sleep apnoea. Clin Respir J. 2010 Jul;4(3): 129-30. 
4. Dursunoglu D, Dursunoglu N. (Heart failure and sleep apnea.). Turk Kardiyol Dern Ars. 2010 Mar;38(2): 135-43.

5. Sharma B, Owens R, Malhotra A. Sleep in congestive heart failure. Med Clin North Am. 2010 May;94(3):447-64.

6. Selim B, Won C, Yaggi HK. Cardiovascular consequences of sleep apnea. Clin Chest Med. 2010 Jun;31(2):203-20.

7. Capampangan DJ, Wellik KE, Parish JM, Aguilar MI, Snyder CR, Wingerchuk D, et al. Is obstructive sleep apnea an independent risk factor for stroke?: a critically appraised topic. Neurologist. 2010 Jul; 16(4):269-73.

8. Manni R, Terzaghi M. Comorbidity between epilepsy and sleep disorders. Epilepsy Res. 2010 May 28.

9. Young T, Palta M, Dempsey J, Skatrud J, Weber S, Badr S. The occurrence of sleep-disordered breathing among middle-aged adults. N Engl J Med. 1993 Apr 29;328(17): 1230-5.

10. Johnson EO, Roth T. An epidemiologic study of sleep-disordered breathing symptoms among adolescents. Sleep. 2006 Sep 1;29(9):1135-42.

11. Schwab RJ, Pasirstein M, Pierson R, Mackley A, Hachadoorian R, Arens R, et al. Identification of upper airway anatomic risk factors for obstructive sleep apnea with volumetric magnetic resonance imaging. Am J Respir Crit Care Med. 2003 Sep 1;168(5):522-30.

12. Schwab RJ. Properties of tissues surrounding the upper airway. Sleep. 1996 Dec;19(10 Suppl):S170-4.

13. Schwab RJ, Pack Al, Gupta KB, Metzger LJ, Oh E, Getsy JE, et al. Upper airway and soft tissue structural changes induced by CPAP in normal subjects. Am J Respir Crit Care Med. 1996 Oct;154(4 P† 1):1106-16.

14. Rosenthal LD, Dolan DC. The Epworth sleepiness scale in the identification of obstructive sleep apnea. J Nerv Ment Dis. 2008 May; 196(5):429-31.

15. Castronovo V, Canessa N, Strambi LF, Aloia MS, Consonni M, Marelli S, et al. Brain activation changes before and after PAP treatment in obstructive sleep apnea. Sleep. 2009 Sep 1:32(9):1161-72.

16. Black JE, Hirshkowitz M. Modafinil for treatment of residual excessive sleepiness in nasal continuous positive airway pressure-treated obstructive sleep apnea/hypopnea syndrome. Sleep. 2005 Apr 1;28(4):464-71.

17. Powell NB, Riley RW, Troell RJ, Li K, Blumen MB, Guilleminault C. Radiofrequency volumetric tissue reduction of the palate in subjects with sleep-disordered breathing. Chest. 1998 May; 113(5): 1163-74.

18. Culbertson WW, Ostler HB. The floppy eyelid syndrome. Am J Ophthalmol. 1981 Oct;92(4):568-75.

19. Fowler AM, Dutton JJ. Floppy eyelid syndrome as a subset of lax eyelid conditions: relationships and clinical relevance (an ASOPRS thesis). Ophthal Plast Reconstr Surg. 2010 May-Jun;26(3): 195-204.

20. Ezra DG, Beaconsfield M, Sira M, Bunce C, Wormald R, Collin R. The associations of floppy eyelid syndrome: a case control study. Ophthalmology. 2010 Apr;117(4):831-8. 21. Mojon DS, Hess CW, Goldblum D, Boehnke M, Koerner F, Gugger M, et al. Normal-tension glaucoma is associated with sleep apnea syndrome. Ophthalmologica. 2002 May-Jun;216(3): 180-4. 
22. Marcus DM, Costarides AP, Gokhale P, Papastergiou G, Miller JJ, Johnson MH, et al. Sleep disorders: a risk factor for normal-tension glaucoma? J Glaucoma. 2001 Jun; 10(3): 177-83.

23. Mojon DS, Hess CW, Goldblum D, Fleischhauer J, Koerner F, Bassetti C, et al. High prevalence of glaucoma in patients with sleep apnea syndrome. Ophthalmology. 1999 May; 106(5): 1009-12.

24. Mojon DS, Hess CW, Goldblum D, Bohnke M, Korner F, Mathis J. Primary openangle glaucoma is associated with sleep apnea syndrome. Ophthalmologica. 2000;214(2):115-8.

25. Abdal H, Pizzimenti JJ, Purvis CC. The eye in sleep apnea syndrome. Sleep Med. 2006 Mar;7(2): 107-15.

26. Karakucuk S, Goktas S, Aksu M, Erdogan N, Demirci S, Oner A, et al. Ocular blood flow in patients with obstructive sleep apnea syndrome (OSAS). Graefes Arch Clin Exp Ophthalmol. 2008 Jan;246(1):129-34.

27. Kargi SH, Altin R, Koksal M, Kart L, Cinar F, Ugurbas SH, et al. Retinal nerve fibre layer measurements are reduced in patients with obstructive sleep apnoea syndrome. Eye (Lond). 2005 May; 19(5):575-9.

28. Mojon DS, Mathis J, Zulauf M, Koerner F, Hess CW. Optic neuropathy associated with sleep apnea syndrome. Ophthalmology. 1998 May; 105(5):874-7.

29. Mojon DS, Hedges TR, 3rd, Ehrenberg B, Karam EZ, Goldblum D, Abou-Chebl A, et al. Association between sleep apnea syndrome and nonarteritic anterior ischemic optic neuropathy. Arch Ophthalmol. 2002 May; 120(5):601-5.

30. Palombi K, Renard E, Levy P, Chiquet C, Deschaux C, Romanet JP, et al. Nonarteritic anterior ischaemic optic neuropathy is nearly systematically associated with obstructive sleep apnoea. Br J Ophthalmol. 2006 Jul;90(7):879-82.

31. Waller EA, Bendel RE, Kaplan J. Sleep disorders and the eye. Mayo Clin Proc. 2008 Nov;83(1 1):1251-61.

32. Bucci FA, Jr., Krohel GB. Optic nerve swelling secondary to the obstructive sleep apnea syndrome. Am J Ophthalmol. 1988 Apr 15;105(4):428-30.

33. Wolin MJ, Brannon WL. Disk edema in an overweight woman. Surv Ophthalmol. 1995 Jan-Feb;39(4):307-14.

34. Purvin VA, Kawasaki A, Yee RD. Papilledema and obstructive sleep apnea syndrome. Arch Ophthalmol. 2000 Dec;1 18(12): 1626-30.

35. Lee AG, Golnik K, Kardon R, Wall M, Eggenberger E, Yedavally S. Sleep apnea and intracranial hypertension in men. Ophthalmology. 2002 Mar; 109(3):482-5.

36. Lee $A G$. Three questions on the role of sleep apnea syndrome in optic disc edema. Arch Ophthalmol. 2001 Aug; 119(8): 1225.

37. Sugita Y, lijima S, Teshima Y, Shimizu T, Nishimura N, Tsutsumi T, et al. Marked episodic elevation of cerebrospinal fluid pressure during nocturnal sleep in patients with sleep apnea hypersomnia syndrome. Electroencephalogr Clin Neurophysiol. 1985 Mar;60(3):214-9.

38. Peter L, Jacob M, Krolak-Salmon P, Petitjean T, Bastuji H, Grange JD, et al. Prevalence of papilloedema in patients with sleep apnoea syndrome: a prospective study. J Sleep Res. 2007 Sep; 16(3):313-8.

- Papilledema does not seem to occur frequently in the setting of obstructive sleep apnea, however, funduscopic exam should be performed in the setting of visual symptoms. 
39. Bruce BB, Kedar S, Van Stavern GP, Monaghan D, Acierno MD, Braswell RA, et al. Idiopathic intracranial hypertension in men. Neurology. 2009 Jan 27;72(4):304-9.

-. Men and women present with different symptom profiles in case of idiopathic intracranial hypertension. Men with $\mathrm{IIH}$ were significantly more likely than women to have obstructive sleep apnea.

40. Wall M, Purvin V. Idiopathic intracranial hypertension in men and the relationship to sleep apnea. Neurology. 2009 Jan 27;72(4):300-1.

41. Leveque TK, Yu L, Musch DC, Chervin RD, Zacks DN. Central serous chorioretinopathy and risk for obstructive sleep apnea. Sleep Breath. 2007 Dec;1 1 (4):253-7.

- Patients with central serous chorioretinopathy may be more likely than the general population to have obstructive sleep apnea.

42. Kloos P, Laube I, Thoelen A. Obstructive sleep apnea in patients with central serous chorioretinopathy. Graefes Arch Clin Exp Ophthalmol. 2008 Sep;246(9): 1225-8.

- A significant association between acute or chronic central serous chorioretinopathy and obstructive sleep apnea exists.

43. Jain AK, Kaines A, Schwartz S. Bilateral central serous chorioretinopathy resolving rapidly with treatment for obstructive sleep apnea. Graefes Arch Clin Exp Ophthalmol. 2010 Jul;248(7): 1037-9.

-. The first known case of bilateral central serous chorioretinopathy is reported which rapidly resolves upon starting treatment with continuous positive airway pressure treatment.

44. Leroux les Jardins G, Glacet-Bernard A, Lasry S, Housset B, Coscas G, Soubrane G. (Retinal vein occlusion and obstructive sleep apnea syndrome). J Fr Ophtalmol. 2009 Jun;32(6):420-4. 